\title{
Reactive oxygen species produced by photodynamic effect induced calcium signal in neurons and astrocytes
}

\author{
Maria Neginskaya $^{1^{*}}$, Elena Berezhnaya $^{1 *}$, Anatoly B. Uzdensky ${ }^{1}$, Andrey Y. Abramov ${ }^{2}$ \\ 1- Laboratory of Molecular Neurobiology, Academy of Biology and Biotechnology, Southern \\ Federal University, pr. Stachki 194/1, Rostov-on-Don 344090, Russia \\ 2- Department of Molecular Neuroscience, UCL Institute of Neurology, Queen Square, London \\ WC1N 3BG, UK
}

*These authors contributed equally to this work

\section{Corresponding authors:}

Anatoly B. Uzdensky

E-mail: auzd@yandex.ru

Maria Neginskaya

E-mail:nma@sfedu.ru

\begin{abstract}
Photodynamic therapy (PDT) leads to production of reactive oxygen species (ROS) and cell destruction due to oxidative stress. We used photodynamic effect of photosensitizer radachlorin to unravel the effect of photo-induced oxidative stress on the calcium signal and lipid peroxidation in primary culture of cortical neurons and astrocytes using live cell imaging. We have found that irradiation in presence of 200 $\mathrm{nM}$ of radachlorin induces calcium signal in primary neurons and astrocytes. Photo-induced neuronal calcium signal depends on internal calcium stores as it was still observed in calcium free medium and could be blocked by depletion of endoplasmic reticulum (ER) stores with inhibitor of sarco-endoplasmic reticulum $\mathrm{Ca}^{2+}$ ATPase (SERCA) thapsigargin. Both inhibitor of phospholipase C activity U73122 and water soluble analogue of vitamin E Trolox suppressed calcium response activated by PDT. We have also observed that the photodynamic effect of radachlorin induces lipid peroxidation in neurons and astrocytes. This data demonstrate that lipid peroxidation induced by PDT in neurons and astrocytes leads to activation of phospholipase $\mathrm{C}$ that results in production of inositol 1,4,5-trisphosphate (IP3).
\end{abstract}

Keywords: photodynamic effect, neurons, astrocytes, calcium signaling, radachlorin

\section{Acknowledgements:}

The work was supported by the Russian Science Foundation (project No. 14-15-00068) and Russian Foundation for Basic Research (project No. 17-04-01728). A.B. Uzdensky was supported by the Ministry of Education and Science of Russian Federation (project No. 6.4951.2017/VU). 
$a$
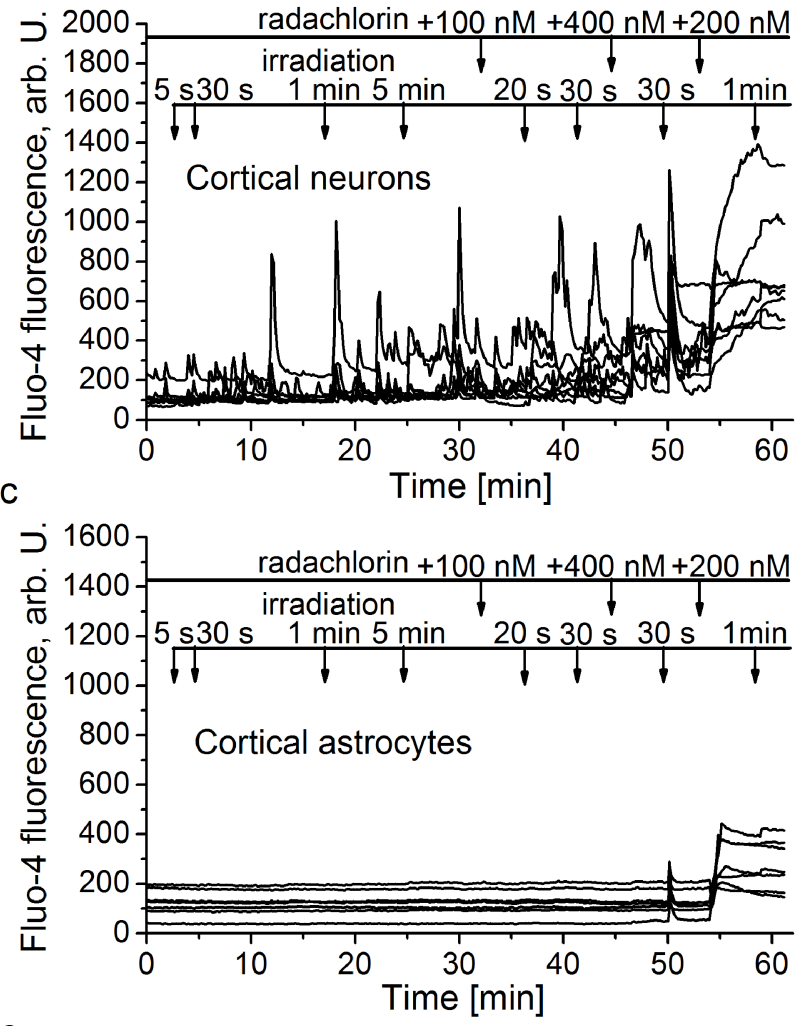

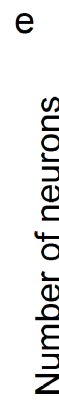

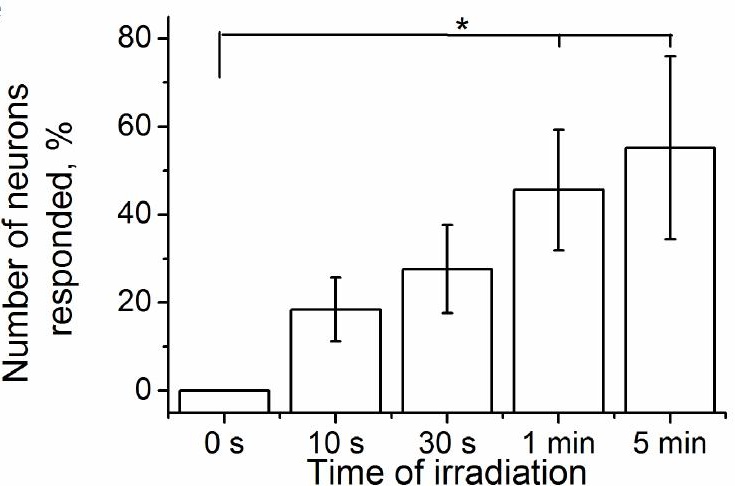

ऽ 2000

$1800-$

radachlorin $+100 \mathrm{nM}+400 \mathrm{nM}+200 \mathrm{nM}$

은 1600

(1) $1400-$

仓 1200

$5 \mathrm{~s} 30 \mathrm{~s} \quad 1 \mathrm{~min} 5 \mathrm{~min} \quad 20 \mathrm{~s} 30 \mathrm{~s} 30 \mathrm{~s} 1 \mathrm{~min}$

Cortical neuron

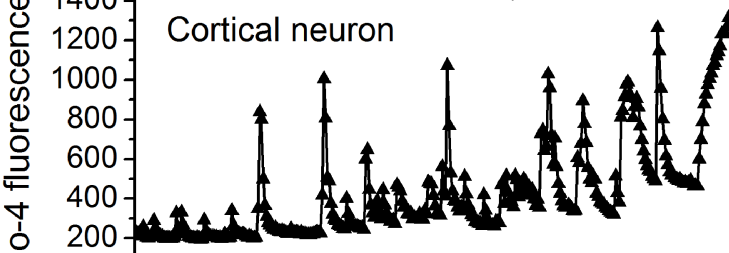

d
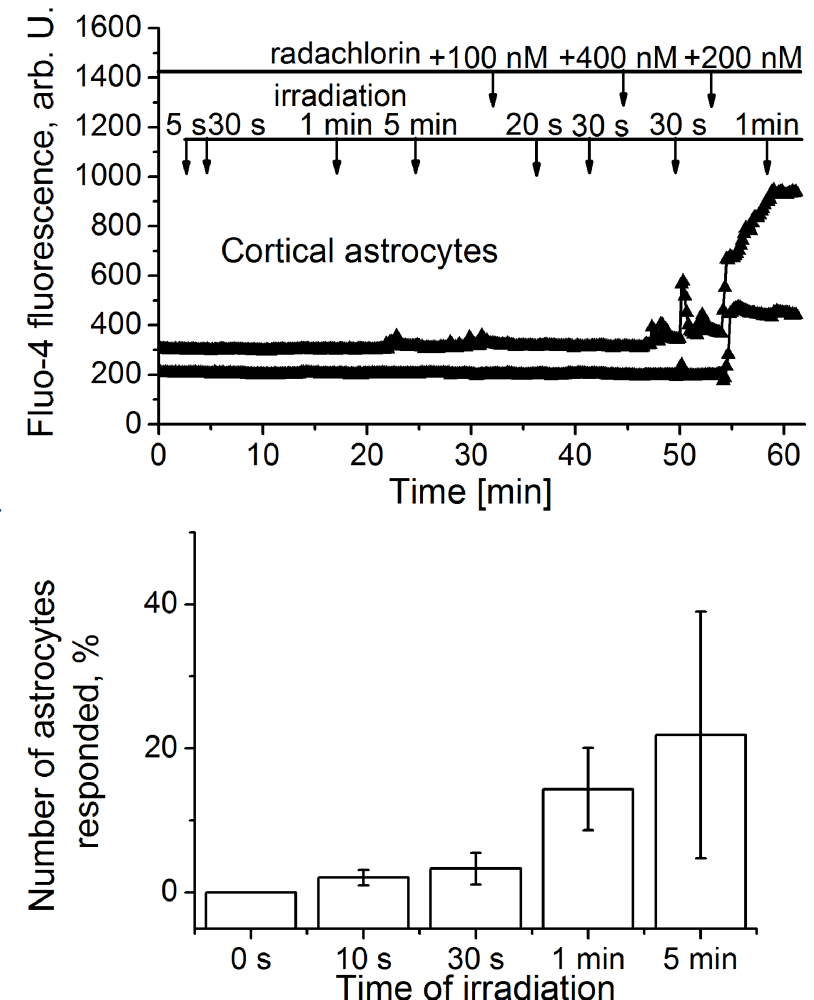


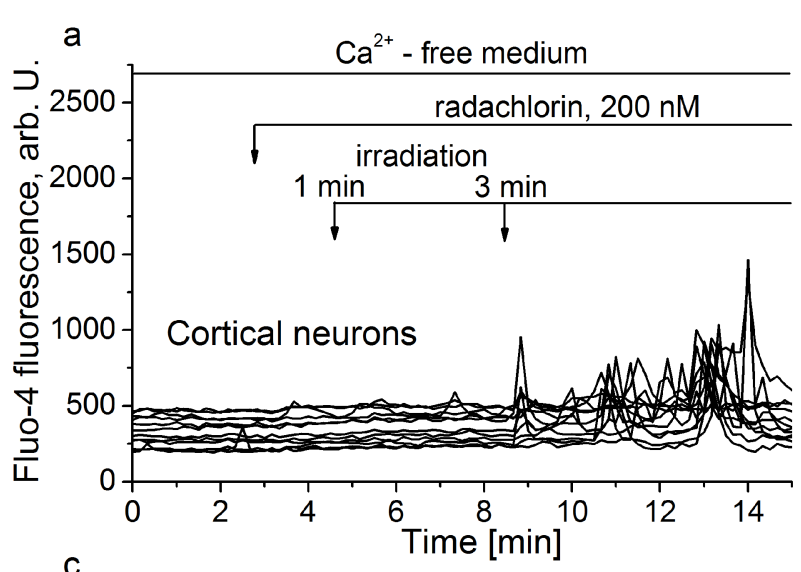

b

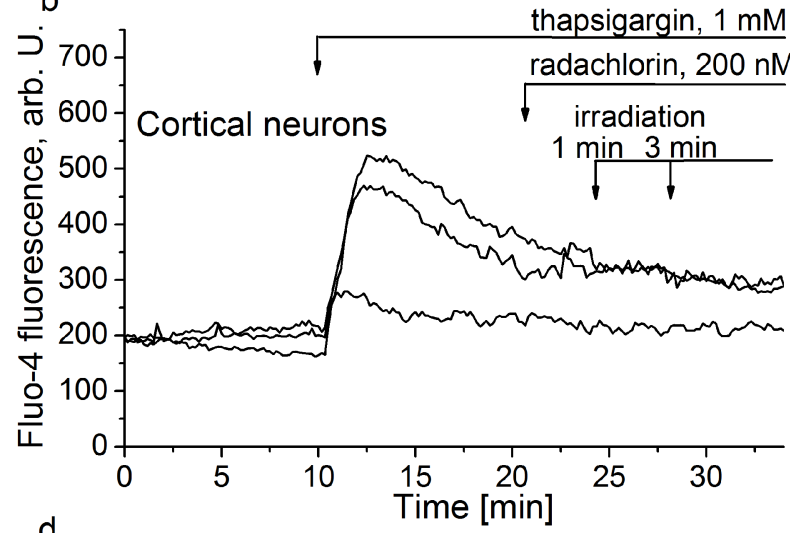

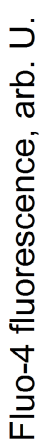

$\mathrm{Ca}^{2+}$ - free medium

irradiation

$1 \mathrm{~min} \quad 3 \mathrm{~min}$

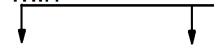

Cortical astrocytes

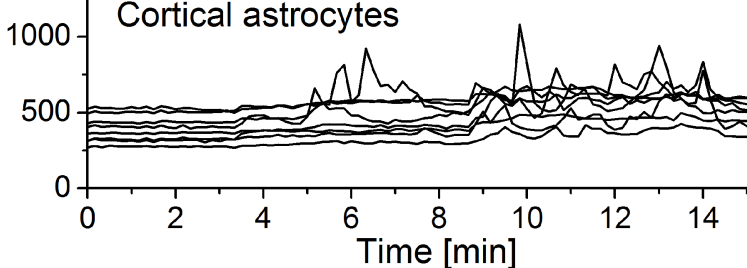

ํํํ

thapsigargin, $1 \mathrm{mM}$ radachlorin, $200 \mathrm{nM}$

Cortical astrocytes irradiation $1 \mathrm{~min} 3 \mathrm{~min}$

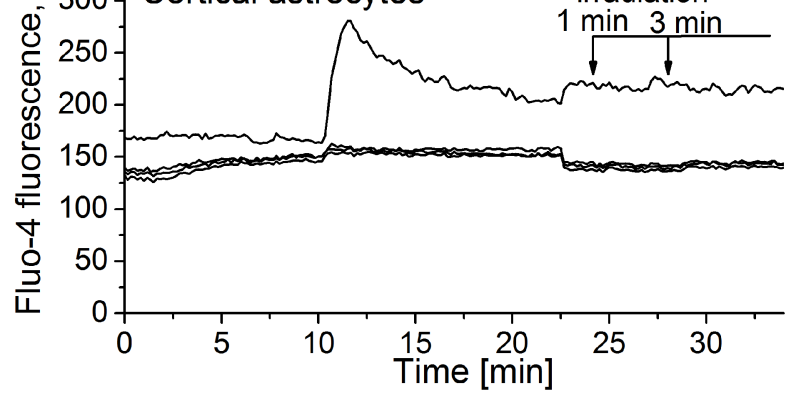


a
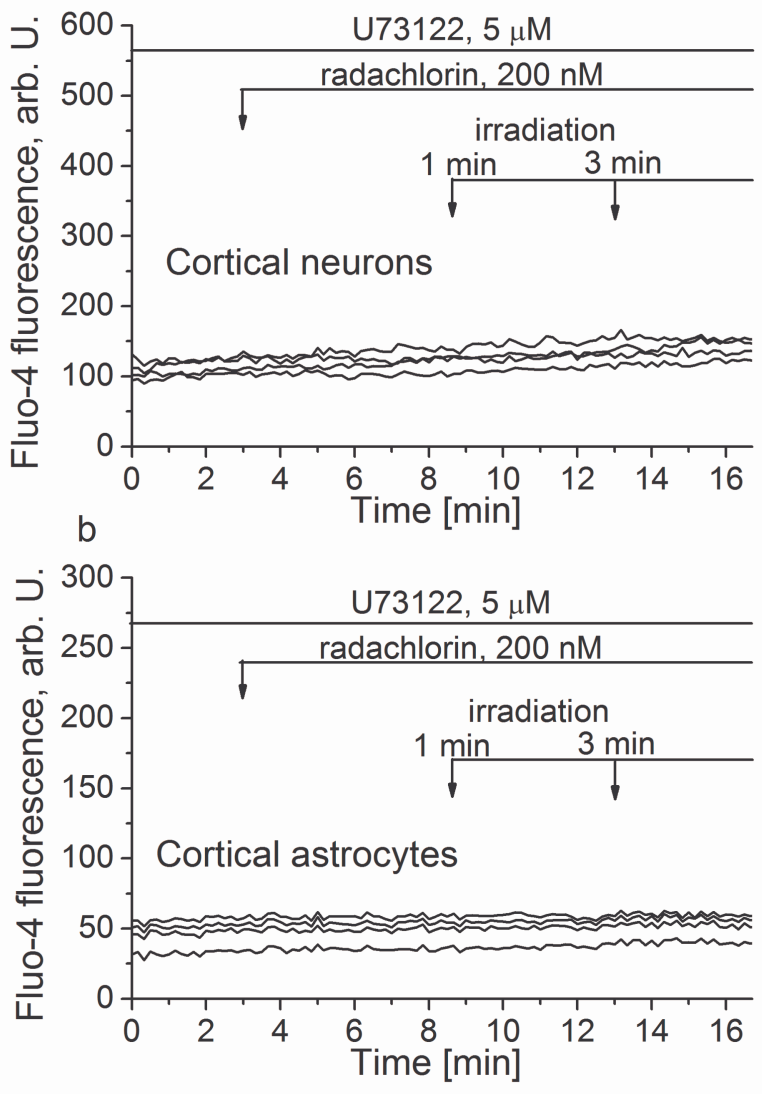


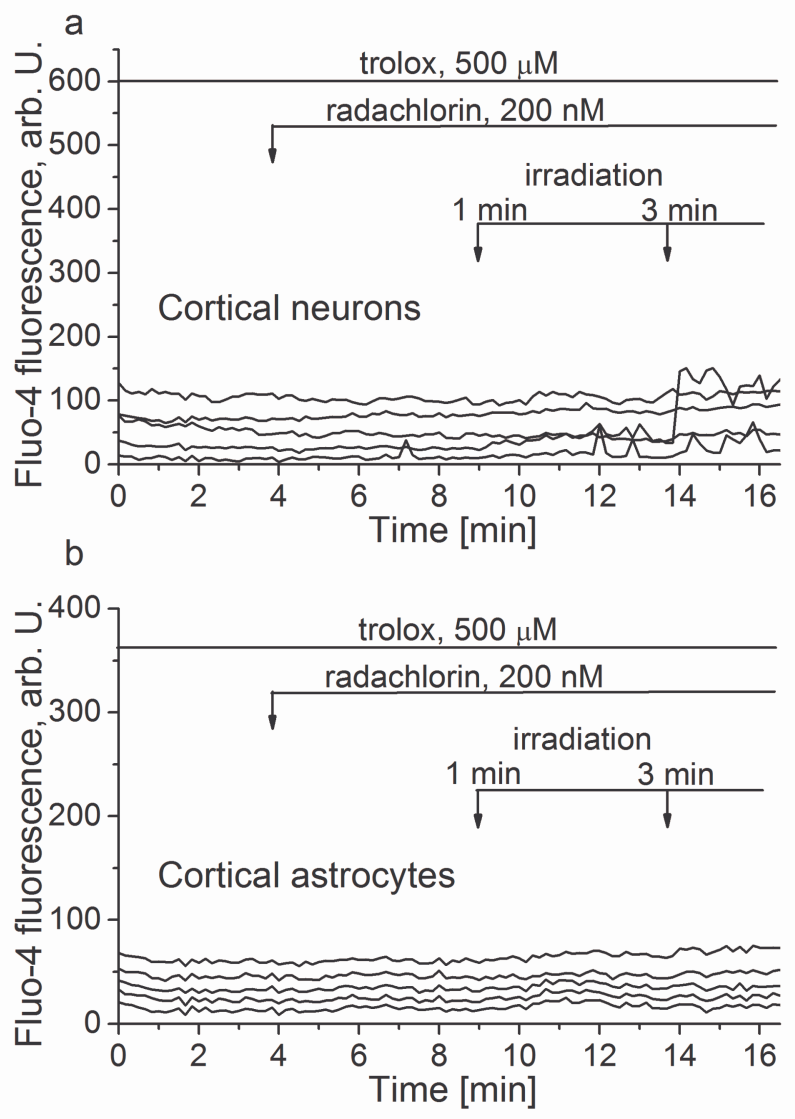



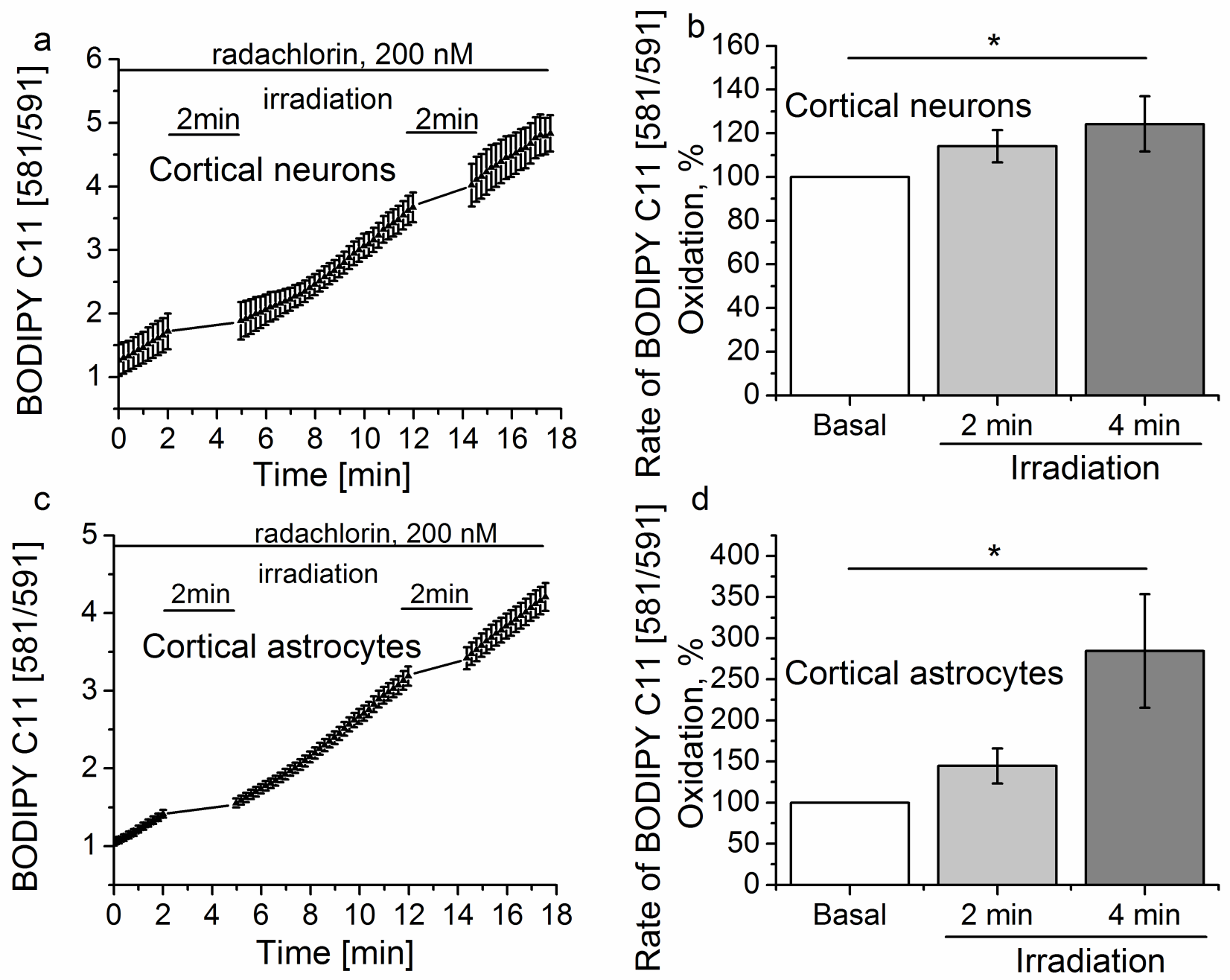


\section{Introduction}

Photodynamic therapy (PDT) is a method used for destruction of brain tumors. PDT is based on production of reactive oxygen species resulting in oxidative stress and death of the cells stained by photosensitizer [1]. Radachlorin is a chlorine derivative photosensitizer currently used for treatment of various types of cancer. It was shown to have a lot of advantages such as rapid accumulation in tumor tissue, high affinity to tumor cells, and fast elimination from the body [2]. However, the mechanism of responses of healthy cell to photo-damage induced by radachlorin still remains unclear.

One of the major effects of photodynamic therapy is induction of the reactive oxygen species production. Excessive production of ROS can lead to oxidative stress followed by triggering of the cell death [3]. However, enzymatic and non-enzymatic free radicals production can play physiological role [4] and can be a stimulus for calcium signaling $[5,6]$.

Calcium ion play important role in regulation of the intracellular processes and cell to cell communication [7]. This intracellular messenger is specifically important in excitable cells, including neurons and astrocytes. Calcium signaling in the brain cells controls most of the physiological processes and also regulates mechanism of the cell death [7].

The ability of PDT to induce an increase in intracellular calcium was shown previously [8-10]. PDT could lead to increase in $\left[\mathrm{Ca}^{2+}\right]_{c}$ through activation of calcium channels in plasma membrane or through release of $\mathrm{Ca}^{2+}$ from internal store of ER via activation of IP3 receptors or PDT mediated SERCA inhibition. The mechanism of the photo-induced calcium signal depends not only on photosensitizer used and its intracellular localization but on the type of the cells treated [11, 12]. The mechanism of photodynamic effect and specifically the photodynamic effect of radachlorin on calcium signal of neurons and glial cells is poorly studied.

In this work, we investigated the mechanism of calcium responses in primary co-culture of neurons and astrocytes in response to photodynamic treatment with radachlorin.

\section{Materials and methods}

\section{Primary co-culture preparation}

Mixed cultures of hippocampal, cortical neurons and glial cells were prepared as described previously $[13,14]$ from Sprague-Dawley rat pups 2-4 days postpartum (UCL breeding colony). Cultures were maintained at $37^{\circ} \mathrm{C}$ in a humidified atmosphere of $5 \% \mathrm{CO} 2$ and $95 \%$ air for a minimum of 12 days before experimental use to ensure the expression of receptors. Neurons were easily distinguishable from glia: they appeared phase bright, had smooth rounded somata and distinct processes, and lay just above the focal plane of the glial layer. Cells were used at 12-18 days in vitro unless differently stated. All animal experiments were performed according to approved guidelines.

Imaging $\left[\mathrm{Ca}^{2+}\right]_{c}$ and Lipid Peroxidation 
For measurement of $\left[\mathrm{Ca}^{2+}\right]_{\mathrm{c}}$, primary co-cultures of neurons and astrocytes were loaded for 40 min at room temperature with $5 \mu \mathrm{M}$ Fluo-4 AM with $0.005 \%$ pluronic in a HBSS (containing $156 \mathrm{mM}$ $\mathrm{NaCl}, 3 \mathrm{mM} \mathrm{KCl}, 2 \mathrm{mM} \mathrm{MgSO} 4,1.25 \mathrm{mM}$ KH2PO4, $2 \mathrm{mM} \mathrm{CaCl} 2,10 \mathrm{mM}$ glucose and $10 \mathrm{mM}$ HEPES, pH adjusted to 7.35 with $\mathrm{NaOH}$. $\mathrm{Ca}^{2+}$-free HBSS also contained 0.5 mM EGTA.

Fluorescence measurements were obtained on an epifluorescence inverted microscope equipped with a $20 \mathrm{x}$ fluorite objective. $\left[\mathrm{Ca}^{2+}\right]_{\mathrm{c}}$ was monitored in single cells using excitation light provided by a xenon arc lamp, the beam passing monochromator at $490 \mathrm{~nm}$ (Cairn Research, Kent, UK). Emitted fluorescence light was reflected through a 515-nm longpass filter to a cooled CCD camera (Retiga; QImaging) and digitized to 12-bit resolution.

For measurement of the lipid peroxidation rate, astrocytes were loaded with $5 \mu \mathrm{M}$ BODIPY C11 [581/591] for $30 \mathrm{~min}$. BODIPY C11 fluorescence was measured using a Zeiss 710 CLSM confocal microscope. BODIPY C11 [581/591] was excited using the 488 and $563 \mathrm{~nm}$ laser line, and fluorescence measured from 505 to $550 \mathrm{~nm}$ and 570 and $630 \mathrm{~nm}$.

All imaging data were collected and analyzed using software Image J.

\section{Photodynamic treatment}

After control registration of baseline of Fluo-4 fluorescence radachlorin (200 nM) was added to the cells and after incubation $(5 \mathrm{~min})$ the cells were irradiated with laser beam $\left(654 \mathrm{~nm}, 0.1 \mathrm{~mW} / \mathrm{cm}^{2}\right) 1$ $\min$ and $3 \mathrm{~min}$. In some experiments the cells were pre-incubated with radachlorin (200 nM) during 5-10 minutes than washed three times and irradiated during $5 \mathrm{~s}, 30 \mathrm{~s}, 1 \mathrm{~min}, 3 \mathrm{~min}$ and $5 \mathrm{~min}$.

The cells downloaded with BODIPY C11 [581/591] were also pre-incubated with $400 \mathrm{nM}$ of radachlorin (5min) and irradiated.

Statistical analysis was performed with the aid of Origin 8 (Microcal Software Inc., Northampton, MA, USA) software. One Way Repeated Measures Anova test was used.

\section{Results}

\section{Photodynamic effect of radachlorin induces calcium signal in neurons and astrocytes}

Application of $200 \mathrm{nM}$ radachlorin to primary co-culture of neurons and astrocytes had no effect on $\left[\mathrm{Ca}^{2+}\right]_{\mathrm{c}}$ of these cells. However, irradiation of radachlorin-loaded cells induced peak-like oscillations in neurons (Fig. 1 a, n=117 cells) and in much less degree in astrocytes (Fig. 1 b, n=126). Typical responses for neuron and astrocyte are shown in figure $1 \mathrm{c}-\mathrm{d}$. Importantly, the number of cells with calcium response was directly dependent on the time of irradiation (Fig. $1 \mathrm{e}-\mathrm{f}$ ).

\section{Photo-induced calcium signal in neurons and astrocytes depends on intracellular $\mathrm{Ca}^{2+}$ stores}

In order to identify the source of the calcium in photo-induced $\left[\mathrm{Ca}^{2+}\right]_{\mathrm{c}}$ changes in neurons and astrocytes we use calcium-free medium (HBSS without $\mathrm{Ca}^{2+}$ plus $0.5 \mathrm{mM}$ EGTA). We found that irradiation of radacholrin-loaded cells in calcium free medium did not block $\left[\mathrm{Ca}^{2+}\right]_{\mathrm{c}}$ changes in both 
neurons (Fig. 2 a, $n=169$ ) and astrocytes (Fig. 2 b, n = 162). Thus, photo-induced calcium signal is independent of external calcium. Considering this, we empty the intracellular (reticular) calcium store by blocking the SERCA by thapsigargin $(1 \mu \mathrm{M})$. Subsequent irradiation of the cells did not induce any changes in $\left[\mathrm{Ca}^{2+}\right]_{\mathrm{c}}$ neurons (Fig. $2 \mathrm{c}, \mathrm{n}=108$ ) and astrocytes (Fig. $2 \mathrm{~d}, \mathrm{n}=143$ ). Thus, irradiation of radachlorin-loaded cells induces release of $\mathrm{Ca}^{2+}$ from ER.

\section{Photodynamic effect of radachlorin leads to phospholipase C activation}

Most common mechanism of the calcium release from ER in neurons and astrocytes is IP3 receptors. IP3 is produced by phospholipase C. We pre-incubate primary co-culture of neurons and astrocytes with specific inhibitor of phospholipase C $-5 \mu \mathrm{M}$ U73122 and found that it completely blocked photo-induced calcium signal in neurons (Fig. 3 a, n = 20) and astrocytes (Fig. 3 b, $n=18$ ). Thus, photodynamic effect of radachlorin induced activation of phospholipase $\mathrm{C}$ and IP3 dependent calcium signal in neurons and astrocytes. Irradiation of photosensitizers induced ROS production $[15,16]$. In order to test if ROS is a trigger for activation of phospholipase C, we used water soluble analogue of vitamin $\mathrm{E}$ - Trolox $(500 \mu \mathrm{M}, 30 \mathrm{~min}$ of pre-incubation). Importantly, pretreatment with antioxidant completely block effect of radachlorin irradiation on $\left[\mathrm{Ca}^{2+}\right]_{\mathrm{c}}$ neurons (Fig. $4 \mathrm{a}, \mathrm{n}=19$ ) and astrocytes (Fig. $4 \mathrm{~b}, \mathrm{n}=19)$.

\section{Photodynamic effect of radachlorin stimulates lipid peroxidation in neurons and astrocytes}

Phospholipase $\mathrm{C}$ can be activated by overproduction of oxidized lipids [5, 6]. Using BODIPY C11 [581/591] as a fluorescent indicator for lipid peroxidation, we measured the photodynamic effect of radachlorin on the rate of the lipid peroxidation. We have found that 2 and 4 minutes photoactivation of radachlorin-loaded cells induced significant increase in the rate of lipid peroxidation (rate of BODIPY C11 [581/591] oxidation rose to $120 \pm 10 \%$ of basal rate for neurons, $n=18, p<0.05$; and to $280 \pm 70 \%$ of basal rate for astrocytes, $n=28 \mathrm{p}<0.01$; Fig. $5 \mathrm{a}-\mathrm{c}$ ). Thus, irradiation with radachlorin induces ROS that trigger lipid peroxidation. Oxidized lipids stimulate phospholipase C, which produces IP3 and initiates calcium release from ER to cytosol.

\section{Discussion}

High selectivity of malignant tissue destruction during PDT is achieved by relatively specific accumulation of photosensitizer in tumor cells. The irradiation of photosensitized cells leads to direct toxic effect, vascular damage and stimulation of immune reactions [17]. Since PDT is used for treatment of brain tumors its effect on healthy tissue should be taken into account. It was shown previously that PDT can stimulate cell death in healthy neurons and glial cells $[18,19]$.

Here we show that irradiation with radachlorin induce lipid peroxidation in primary co-culture of neurons and astrocytes. Irradiation can produce it acting directly to lipids or indirectly through production of ROS. Considering the effect of Trolox and production of ROS during photodynamic effect of chlorine 
derivative photosensitizers $[15,16]$ we can suggest that photodynamic effect of radachlorin induces production of ROS that is trigger for subsequent lipid peroxidation.

Lipid peroxidation is a trigger for membrane instability and further toxicity by its byproduct [20]. Lower or moderate level of lipid peroxidation can induce activity of the number of phospholipases including phospholipase $\mathrm{C}[4,21,22]$. In our experiments lipid peroxidation induced activation of phospholipase $\mathrm{C}$ that can be proven by inhibition with U73122. This activation play two important functions - removal of oxidized lipids and initiation of the calcium signal.

One of the interesting characteristics of the photodynamic effect of radachlorin on the calcium signal of neurons and astrocytes is that increase in the time of irradiation increases the number of cells with response, but not the amplitude of the signal (Fig. 1). It suggests that such mode of irradiation does not induce calcium signal of any other nature (such as permeabilization of the membranes). Difference in the higher affinity of the neurons to radachlorin irradiation and subsequent calcium signal compared to astrocytes can be explained by higher level of endogenous antioxidants (GSH) in glia compared to neurons [23].

Photo-induced calcium signal in neurons and astrocytes can play protective role: in stimulation of the number endogenous processes for cell protection or just for utilization of oxidized lipids by phospholipase C. However, irradiation of the radachlorin-loaded neurons in some of the brain areas can induce this signal that can interfere with regulatory signal in CNS.

Calcium signal is energy consuming process and prolonged and intensive elevation in $\left[\mathrm{Ca}^{2+}\right]_{\mathrm{c}}$ in combination with disruption in energy metabolism can induce energy deprivation and excitotoxicity [24, 25]. Considering the effect of PDT on the energy metabolism [26], activation of the calcium signal in neurons and astrocytes by photodynamic treatment with radachlorin can be potentially damaging for healthy tissue.

Conflict of Interest: The authors declare that they have no conflict of interest.

\section{References}

1. Quirk BJ, Brandal G, Donlon S, et al (2015) Photodynamic therapy ( PDT ) for malignant brain tumors - Where do we stand? Photodiagnosis Photodyn Ther 12:530-544. doi: 10.1016/j.pdpdt.2015.04.009

2. Juzeniene A (2009) Chlorin e6-based photosensitizers for photodynamic therapy and photodiagnosis. Photodiagnosis Photodyn Ther 6:94-96. doi: 10.1016/j.pdpdt.2009.06.001

3. Gandhi S, Abramov AY (2012) Mechanism of oxidative stress in neurodegeneration. Oxid Med Cell Longev 2012:428010 1-11. doi: 10.1155/2012/428010

4. Angelova PR, Abramov AY (2016) Functional Role of Mitochondrial Reactive Oxygen Species in Physiology. Free Radic Biol Med 100:81-85. doi: 10.1016/j.freeradbiomed.2016.06.005

5. Domijan A-M, Kovac S, Abramov AY (2012) Impact of fumonisin B1 on glutamate toxicity and low magnesium-induced seizure activity in neuronal primary culture. Neuroscience 202:10-16. 
doi: 10.1016/j.neuroscience.2011.12.005

6. Vaarmann A, Gandhi S, Abramov AY (2010) Dopamine induces Ca2+ signaling in astrocytes through reactive oxygen species generated by monoamine oxidase. J Biol Chem 285:2501825023. doi: 10.1074/jbc.M110.111450

7. Carafoli E, Krebs J (2016) Why Calcium? How Calcium Became the Best Communicator. J Biol Chem 291:20849-20857. doi: 10.1074/jbc.R116.735894

8. Almeida RD, Manadas BJ, Carvalho AP, Duarte CB (2004) Intracellular signaling mechanisms in photodynamic therapy. Biochim Biophys Acta 1704:59-86. doi: 10.1016/j.bbcan.2004.05.003

9. Giorgi C, Bonora M, Missiroli S, et al (2015) Intravital imaging reveals p53-dependent cancer cell death induced by phototherapy via calcium signaling. Oncotarget 6:1435-45. doi:

10.18632/oncotarget.2935

10. Hu SL, Du P, Hu R, et al (2014) Imbalance of Ca2+ and K+ fluxes in C6 glioma cells after PDT measured with scanning ion-selective electrode technique. Lasers Med Sci 29:1261-1267. doi: 10.1007/s10103-014-1518-3

11. Mroz P, Yaroslavsky A, Kharkwal GB, Hamblin MR (2011) Cell death pathways in photodynamic therapy of cancer. Cancers (Basel) 3:2516-2539. doi: 10.3390/cancers3022516

12. Abrahamse H, Hamblin MR (2016) New photosensitizers for photodynamic therapy. Biochem J 473:347-364. doi: 10.1042/BJ20150942

13. Domijan A-M, Abramov AY (2011) Fumonisin B1 inhibits mitochondrial respiration and deregulates calcium homeostasis-Implication to mechanism of cell toxicity. Int J Biochem Cell Biol 43:897-904. doi: 10.1016/j.biocel.2011.03.003

14. Angelova PR, Ludtmann MHR, Horrocks MH, et al (2016) Ca2+ is a key factor in alphasynuclein-induced neurotoxicity. J Cell Sci 129:1792-1801. doi: 10.1242/jcs.180737

15. Berezhnaya E, Neginskaya M, Uzdensky AB, Abramov AY (2017) Photo-Induced Oxidative Stress Changes Mitochondrial Metabolism in Neurons and Astrocytes. Mol. Neurobiol.

16. Zenkevich E, Sagun E, Knyukshto V, et al (1996) Photophysical and photochemical properties of potential porphyrin and chlorin photosensitizers for PDT. J Photochem Photobiol B Biol 33:171180. doi: 10.1016/1011-1344(95)07241-1

17. Agostinis P, Berg K, Cengel K., et al (2011) Photodynamic Terapy of cancer: an update. CA Cancer J Clin 61:250-281. doi: 10.3322/caac.20114.PHOTODYNAMIC

18. Neginskaya MA, Berezhnaya EV, Rudkovskii MV, et al (2014) Photodynamic effect of Radachlorin on nerve and glial cells. Photodiagnosis Photodyn Ther 11:357-364. doi: 10.1016/j.pdpdt.2014.06.005

19. Shinoda Y, Takahashi T, Akimoto J, et al (2017) Comparative photodynamic therapy cytotoxicity of mannose-conjugated chlorin and talaporfin sodium in cultured human and rat cells. J Toxicol Sci 42:111-119. doi: 10.2131/jts.42.111

20. Hauck AK, Bernlohr DA (2016) Oxidative stress and lipotoxicity. J Lipid Res 57:1976-1986. doi: 10.1194/jlr.R066597 
21. Domijan A-M, Kovac S, Abramov AY (2014) Lipid peroxidation is essential for phospholipase C activity and the inositol-trisphosphate-related $\mathrm{Ca}^{2+}$ signal. J Cell Sci 127:21-6. doi: $10.1242 /$ jcs. 138370

22. Timusheva YT, Mareninova OA, Vagina ON, et al (1998) The role of membrane structure in the activation of mitochondrial phospholipases. 1. Activation of mitochondrial phospholipases by lipid peroxidation products. Membr Cell Biol 12:41-9.

23. Dringen R, Gutterer JM, Hirrlinger J (2000) Glutathione metabolism in brain. Eur J Biochem 267:4912-4916. doi: 10.1046/j.1432-1327.2000.01597.x

24. Kovac S, Domijan A-M, Walker MC, Abramov AY (2012) Prolonged seizure activity impairs mitochondrial bioenergetics and induces cell death. J Cell Sci 125:1796-806. doi:

10.1242/jcs.099176

25. Abramov AY, Duchen MR (2010) Impaired mitochondrial bioenergetics determines glutamateinduced delayed calcium deregulation in neurons. Biochim Biophys Acta - Gen Subj 1800:297304. doi: 10.1016/j.bbagen.2009.08.002

26. Hilf R (2007) Mitochondria are targets of photodynamic therapy. J Bioenerg Biomembr 39:85-89. doi: 10.1007/s10863-006-9064-8 


\section{FIGURE LEGENDS}

Fig. 1 Irradiation in presence of radachlorin induces increase in $\left[\mathrm{Ca}^{2+}\right]_{\mathrm{c}}$ neurons and astrocytes Irradiation with radachlorin induce peak-like oscillations of $\left[\mathrm{Ca}^{2+}\right]_{c}$ in neurons ( $\mathrm{a}$ and $\mathrm{b}$ ) and astrocytes (c and d). Each trace represents changes in the cytosolic $\mathrm{Ca}^{2+}$ in a single cell. The cells were pre-incubated with radachlorin ( $200 \mathrm{nM}, 10 \mathrm{~min}$ ) than washed and irradiated; during the experiment the concentration of radachlorin was increased several times. Longer time of irradiation results in increase of the number of cells (e - neurons, f - astrocytes) responded to photodynamic effect of radachlorin. Data on (e) and (f) panels are presented as the mean \pm s.e.m. $*$ - $p<0.05$.

Fig. $2\left[\mathrm{Ca}^{2+}\right]_{\mathrm{c}}$ changes in response to irradiation with radachlorin are dependent on intracellular $\mathrm{Ca}^{2+}$ stores in neurons and astrocytes

Removal of external $\mathrm{Ca}^{2+}\left(\mathrm{Ca}^{2+}\right.$-free HBSS with $0.5 \mathrm{mM}$ EDTA) does not abolish photo-induced $\mathrm{Ca}^{2+}$ responses in neurons (a) and astrocytes (c). Depletion of the intracellular $\mathrm{Ca}^{2+}$ pool by application of the inhibitor of ER $\mathrm{Ca}^{2+}$ pump, thapsigargin $(1 \mu \mathrm{M})$, abolishes the photo-induced $\mathrm{Ca}^{2+}$ signal in neurons (b) and astrocytes (d). Each trace represents changes in the cytosolic $\mathrm{Ca}^{2+}$ in a single cell. The cells were irradiated in presence of radachlorin $(200 \mathrm{nM})$ during 1 and $3 \mathrm{~min}$.

Fig. 3 Impact of inhibitor of phospholipase $\mathrm{C}$ activity on photo-induced $\mathrm{Ca}^{2+}$ signal in neurons and astrocytes

Pre-incubation with inhibitor of phospholipase C activity, U73122 (5 $\mu \mathrm{M}, 15 \mathrm{~min})$, blocked changes in $\left[\mathrm{Ca}^{2+}\right]_{\mathrm{c}}$ in response to irradiation (1 and $3 \mathrm{~min}$ ) in presence of $200 \mathrm{nM}$ of radachlorin in neurons (a) and astrocytes (b). Each trace represents changes in the cytosolic $\mathrm{Ca}^{2+}$ in a single cell.

Fig. 4 Effect of water-soluble analogue of vitamin E, Trolox, on photo-induced $\mathrm{Ca}^{2+}$ signal in neurons and astrocytes

Pre-treatment with antioxidant, Trolox $(500 \mu \mathrm{M}, 30 \mathrm{~min})$, that inhibits lipid peroxidation almost completely blocked $\mathrm{Ca}^{2+}$ changes in response to irradiation (1 and $\left.3 \mathrm{~min}\right)$ with radachlorin $(200 \mathrm{nM})$ in neurons (a) and astrocytes (b). Each trace represents changes in the cytosolic $\mathrm{Ca}^{2+}$ in a single cell.

Fig. 5 Effect of photodynamic treatment on lipid peroxidation in neurons and astrocytes Irradiation with radachlorin $(400 \mathrm{nM})$ induces increase in the rate of lipid peroxidation in both neurons (a and b) and astrocytes (c and d). Traces in panels (a) and (c) represent the mean \pm s.e.m. fluorescence measured in neurons and astrocytes in a representative experiment.

Panels (b) and (d) represent increase in the rate of lipid peroxidation as a percentage of the basal rate of BODIPY C11 [581/591] oxidation.

The cells were pre-incubated with radachlorin $(5 \mathrm{~min})$ than irradiated two times for 2 minutes. * $-\mathrm{p}<0.05$ 